\title{
Article \\ Novel Phage Lysin Abp013 against Acinetobacter baumannii
}

\author{
Joash Jun Keat Chu ${ }^{1,2}{ }^{(D}$, Wee Han Poh ${ }^{3}$, Nabilah Taqiah Binte Hasnuddin ${ }^{3}$, En Yi Hew ${ }^{1}$, Linh Chi Dam ${ }^{1}$, \\ Abbas El Sahili ${ }^{2} \mathbb{0}$, Scott A. Rice ${ }^{2,3,4, *}$ and Boon Chong Goh ${ }^{1, *} \mathbb{C}$
}

1 Antimicrobial Resistance Interdisciplinary Research Group, Singapore-MIT Alliance for Research and Technology Centre, Singapore 138602, Singapore; jchu011@e.ntu.edu.sg (J.J.K.C.); s10177065@connect.np.edu.sg (E.Y.H.); LINHCHI001@e.ntu.edu.sg (L.C.D.)

2 School of Biological Sciences, Nanyang Technological University, Singapore 637551, Singapore; aelsahili@ntu.edu.sg

3 Singapore Centre for Environmental Life Sciences Engineering, School of Biological Sciences, Nanyang Technological University, Singapore 637551, Singapore; whpoh@ntu.edu.sg (W.H.P.); nabilah.taqiah@ntu.edu.sg (N.T.B.H.)

4 The Ithree Institute, University of Technology Sydney, Sydney, NSW 2007, Australia

* Correspondence: rscott@ntu.edu.sg (S.A.R.); boonchong@smart.mit.edu (B.C.G.)

Citation: Chu, J.J.K.; Poh, W.H.; Hasnuddin, N.T.B.; Hew, E.Y.; Dam, L.C.; Sahili, A.E.; Rice, S.A.; Goh, B.C. Novel Phage Lysin Abp013 against Acinetobacter baumannii. Antibiotics 2022, 11, 169. https://doi.org/ $10.3390 /$ antibiotics11020169

Academic Editors: Hongping Wei and Carlos M. Franco

Received: 9 December 2021

Accepted: 25 January 2022

Published: 28 January 2022

Publisher's Note: MDPI stays neutral with regard to jurisdictional claims in published maps and institutional affiliations.

Copyright: (C) 2022 by the authors. Licensee MDPI, Basel, Switzerland. This article is an open access article distributed under the terms and conditions of the Creative Commons Attribution (CC BY) license (https:// creativecommons.org/licenses/by/ $4.0 /)$.

\begin{abstract}
As antimicrobial resistance (AMR) continues to pose an ever-growing global health threat, propelling us into a post-antibiotic era, novel alternative therapeutic agents are urgently required. Lysins are bacteriophage-encoded peptidoglycan hydrolases that display great potential as a novel class of antimicrobials for therapeutics. While lysins against Gram-positive bacteria are highly effective when applied exogenously, it is challenging for lysins to access and cleave the peptidoglycan of Gram-negative bacteria due to their outer membrane. In this study, we identify a novel phage lysin Abp013 against Acinetobacter baumannii. Abp013 exhibited significant lytic activity against multidrug-resistant strains of A. baumannii. Notably, we found that Abp013 was able to tolerate the presence of human serum by up to $10 \%$. Using confocal microscopy and LIVE/DEAD staining, we show that Abp013 can access and kill the bacterial cells residing in the biofilm. These results highlight the intrinsic bacteriolytic property of Abp013, suggesting the promising use of Abp013 as a novel therapeutic agent.
\end{abstract}

Keywords: phage lysin; endolysin; multidrug resistance; Acinetobacter baumannii; novel antibacterial agent

\section{Introduction}

The inappropriate and extensive use of antibiotics over the past few decades have led to the emergence of antimicrobial resistance (AMR) [1,2]. This phenomenon is particularly startling in Gram-negative bacteria, including multidrug-resistant (MDR) Acinetobacter baumannii, Klebsiella pneumoniae, and Pseudomonas aeruginosa, which are responsible for serious nosocomial infections that often lead to high rates of morbidity and mortality [3]. Antibiotics, which are indispensable for bacterial infection treatments, have become less effective against these MDR bacteria [4,5]. Thus, the decline in antibiotic efficacy and the lack of novel antibiotics have placed us closer to a post-antibiotic era, necessitating the prompt and immediate search as well as the development of novel alternative antimicrobial approaches to combat the serious threat posed by MDR bacterial infections [6].

Among the various alternative antibacterial agents, a promising approach involves the use of lysins. Lysins, also known as endolysins, are peptidoglycan hydrolases that hydrolyze crucial covalent bonds of the peptidoglycan layer required for maintaining the structural integrity of the cell wall [7]. Bacteriophages utilize lysins to penetrate the bacterial host during infection, and destroy the peptidoglycan to release the phage progeny during the phage lytic cycle [8]. Compared to conventional antibiotics, lysins offer numerous 
advantages, such as a lower probability of developing resistance [9], high specificity and selectivity for bacterial pathogens [10,11], and the ability to act on bacterial biofilms [12].

Previous studies have demonstrated the potential of utilizing recombinantly expressed lysins and applying them exogenously, a notion known as "lysis from without". Generally, Gram-positive lysins are highly effective, resulting in the rapid lysis and death of the targeted bacteria due to a readily accessible peptidoglycan [13,14]. In contrast, the antimicrobial effects of exogenously added lysins are greatly diminished in Gram-negative bacteria, due to the presence of a protective outer membrane barrier that restricts the access and entry of lysins to the peptidoglycan through the bacterial lipopolysaccharide (LPS)covered surfaces [15-17]. As such, few naturally occurring lysins have been reported to display antimicrobial activity against Gram-negative bacteria $[15,18,19]$. However, in recent years, studies reporting the simultaneous application of outer membrane permeabilizers (OMPs) and lysins, as well as the development of engineered lysins (Artilysins) through the modification of charged amino acid residues at their terminal region have shown improved antibacterial activity, overcoming the hindrance posed by the outer membrane $[16,20]$.

While most lysins targeting Gram-positive bacteria are specific in targeting a single host species or genus, lysins against Gram-negative bacteria are typically found to be effective across multiple bacterial species [21,22]. The reason for their broad host-range can be ascribed to the cationic tail that facilities the penetration of lysins through the outer membrane of Gram-negative bacteria. Furthermore, some lysins targeting Gram-negative bacteria were found to have a non-enzymatic mechanism of action, such as antimicrobial peptide-like elements in the lysin sequences that aid in the destabilization of the outer membrane [23,24].

In this present study, we identify a novel phage lysin termed Abp013 against $A$. baumannii, and characterize it for its optimal dose concentration, $\mathrm{pH}$, salt, and human serum tolerance. The lytic spectra of Abp013 are determined against a panel of MDR bacteria species, including A. baumannii, K. pneumoniae, and P. aeruginosa. Abp013 is also evaluated for its potential to kill bacteria residing inside a bacterial biofilm. The results obtained elucidate the intrinsic bacteriolytic property of Abp013, suggesting the promising use of Abp013 as a novel therapeutic agent. Lastly, our study discusses the potential in engineering Abp013 to create better lysins with higher specificity and selectivity against MDR Gram-negative bacteria.

\section{Results}

\subsection{Identification and Bioinformatic Analysis of Abp013}

The gene of lysin Abp013 was identified from the genome of an A. baumannii bacteriophage, $\varphi \mathrm{Abp} 2$, and it was annotated as a secretion activator protein (ABP2_013) under the accession number MF346584.1 [25]. The analysis of the protein sequence using the NCBI Conserved Domain Database (CDD) and Simple Modular Architecture Research Tool (SMART) [26], revealed a glycoside hydrolase family 108 at the N-terminal, while a peptidoglycan-binding domain was located at the C-terminal (Figure 1A). The confidently predicted domains analyzed via SMART are listed in Supplementary Table S1.

A phylogenetic analysis utilizing the ClustalW alignment of Abp013 with other previously reported Gram-negative lysins showed a low similarity with other reported lysins (Figure 1B). As LysSAP26 and KZ144 share a common ancestor with Abp013, further analysis via the MUSCLE multiple alignment tool [27] revealed a low level of similarity of Abp013 with LysSAP26 and KZ144, suggesting the novelty of Abp013 (Supplementary Figure S1).

\subsection{Expression, Purification, and Functional Characterization of Abp013}

\subsubsection{Expression and Purification of Abp013}

The gene of Abp013 was cloned into a pNIC-CH vector, transformed in the BL21(DE3)T1R Escherichia coli Rosetta strain. The Abp013 protein was purified via affinity chromatography using Ni-charged magnetic beads. The SDS-PAGE showed a single band slightly below the $20 \mathrm{kDa}$ ladder, consistent with the estimated molecular mass of $19.5 \mathrm{kDa}$ 
(Figure 2A). A high yield of $26 \mathrm{mg}$ of purified Abp013 was obtained from a $1 \mathrm{~L}$ culture, which could be attributed to the optimization of the codon usage of the recombinant gene for E. coli expression.

A

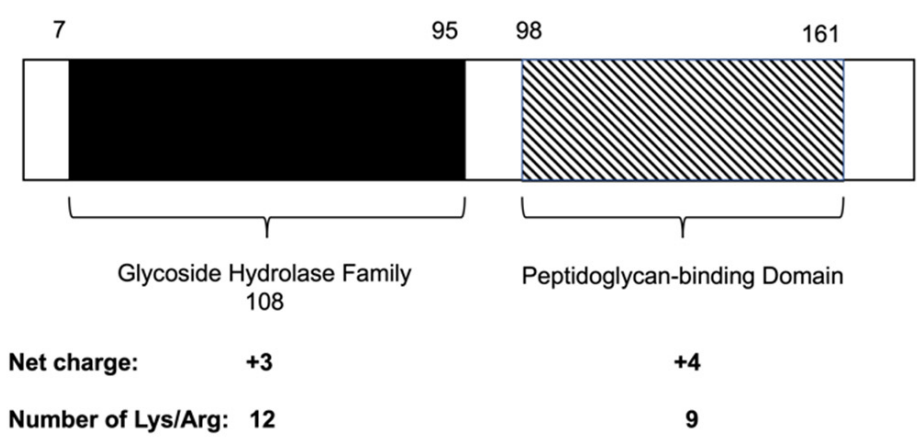

B

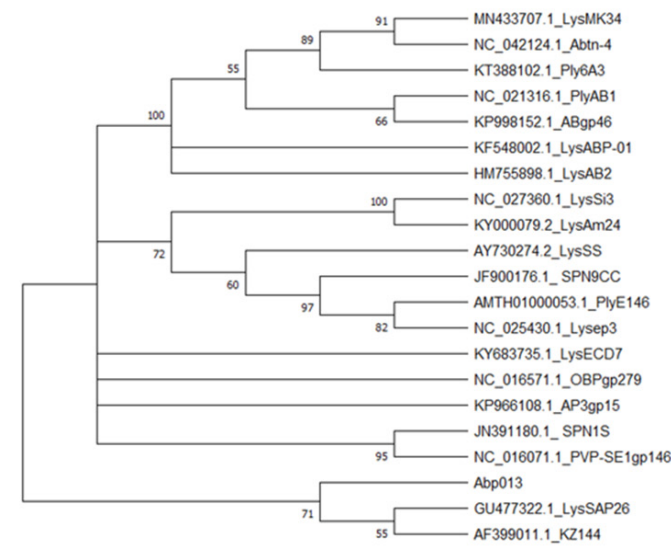

Figure 1. Bioinformatic analysis of Abp013. (A) Schematic diagram of the domain organization of Abp013. The glycoside hydrolase family 108 (net charge: +2 ) is located between amino acid residues 7 and 95, while the peptidoglycan-binding domain (net charge: +3 ) is located between residues 98 and 161. (B) Bootstrap consensus tree showing the phylogenetic relationship of Abp013 and previously reported Gram-negative lysins. The nucleotide sequences were aligned via ClustalW, and the evolutionary history was inferred via the Neighbor-Joining tree method using MEGA11 software.

\subsubsection{Dose Response of Abp013}

To determine the optimal dose concentration of Abp013 for the subsequent experiments, the lytic activity of Abp013 $(0.39 \mu \mathrm{g} / \mathrm{mL}$ to $800 \mu \mathrm{g} / \mathrm{mL})$ was measured against A. baumannii ATCC 17961 by performing a bactericidal assay. At $25 \mu \mathrm{g} / \mathrm{mL}$, Abp013 was able to achieve $>90 \%$ reduction in $\log$ CFU, while concentrations beyond $25 \mu \mathrm{g} / \mathrm{mL}$ showed maximal lytic activity and achieved full log-CFU reduction in the number of viable bacterial cells (Figure 2B).

\subsubsection{Abp013 Characterization at Various $\mathrm{pH}$ and Salt Concentrations}

The characterization of the bactericidal activity of Abp013 at different $\mathrm{pH}$ levels at $100 \mu \mathrm{g} / \mathrm{mL}$, showed that Abp013 had high killing activity at $\mathrm{pH}$ 6.0, 8.0, and 9.0 (Figure 2C). While, at $\mathrm{pH} 7.0$, there was a marked reduction in the killing activity, achieving only a $\sim 1.3-\log$ CFU reduction. This assay was repeated at a low lysin concentration of $10 \mu \mathrm{g} / \mathrm{mL}$ and it revealed both pH 6 and 8 are optimal (Supplementary Figure S2). $\mathrm{pH} 6.0$ was chosen for the subsequent assays because it is a physiologically relevant $\mathrm{pH}$ for A. baumannii $[28,29]$.

We then examined the halotolerance of $\mathrm{Abp} 013$ and the effects of varying $\mathrm{NaCl}$ concentrations on its killing efficacy. The log-phase $A$. baumannii cells were incubated with $100 \mu \mathrm{g} / \mathrm{mL}$ of Abp013 in buffers containing $0-500 \mathrm{mM}$ of $\mathrm{NaCl}$. The bacterial viability remained relatively constant throughout all the tested $\mathrm{NaCl}$ concentrations. The maximal killing activity of Abp013 was observed at $50 \mathrm{mM} \mathrm{NaCl}$, and the lytic activity was significantly reduced when the concentration was raised to $100 \mathrm{mM} \mathrm{NaCl}$ (2-log CFU reduction) (Figure 2D). The subsequent increase in $\mathrm{NaCl}$ concentrations beyond $100 \mathrm{mM}$ abolished the killing activity of Abp013. 
A

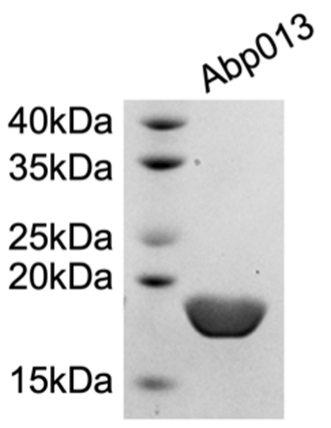

B

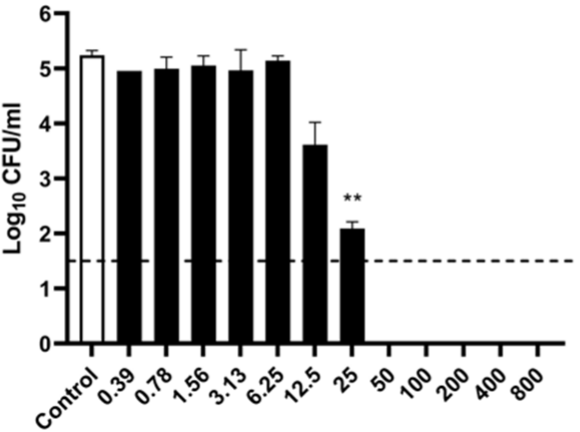

C

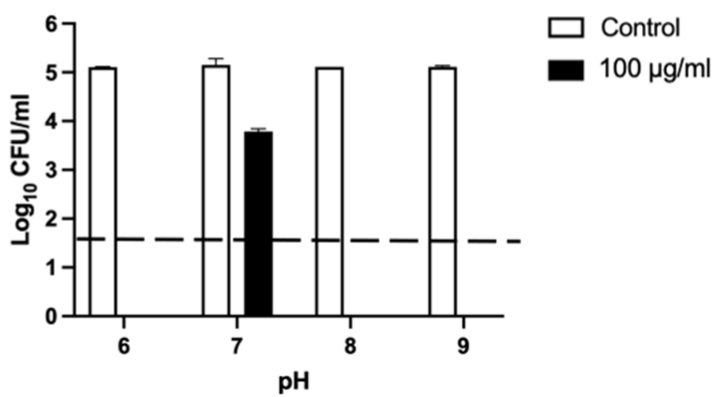

Abp013 concentration $(\mu \mathrm{g} / \mathrm{ml})$

D

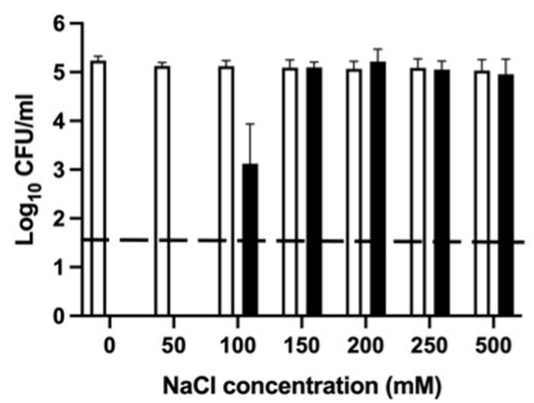

E

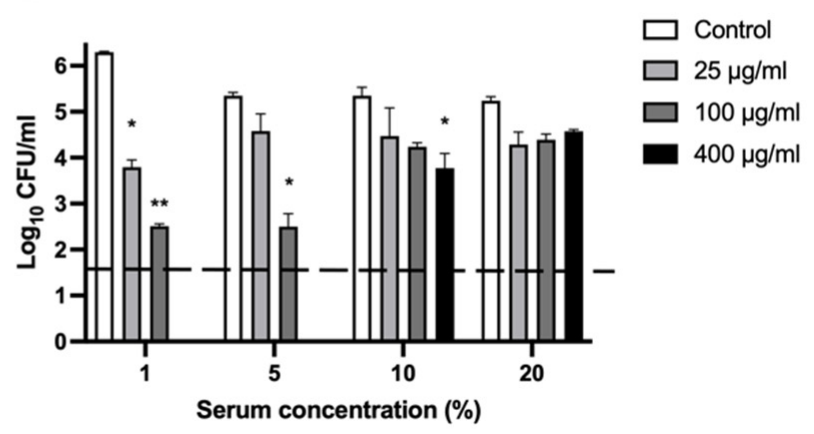

Figure 2. Purification of Abp013. (A) SDS-PAGE (12\%) analysis of Abp013. Gel shows a highly purified $19.5 \mathrm{kDa}$ Abp013 containing a C-terminal 6x HIS needed for affinity chromatography purification. Characterization of Abp013. The dose-response of Abp013 was determined (B) and the lytic activity of Abp013 was tested at various $\mathrm{pH}$ buffers (C) and under different salt concentrations (D). The tolerance of Abp013 towards human serum were tested as well (E). The number of $\log 10 \mathrm{CFU} / \mathrm{mL}$ was determined through plating 10-fold serial dilution in a bactericidal assay and compared with buffer-treated negative controls. Statistical significance was determined by a two-tailed Student's $t$-test with Welch's correction. ${ }^{*} p<0.05 ;{ }^{* *} p<0.01$. The dashed line indicates the limit of detection. The experiments were carried out in biological duplicates; error bars represent the standard deviation.

\subsubsection{Efficacy of Abp013 in Serum}

A challenge in the application of Gram-negative lysins is the abolished killing activity in the presence of human serum. The activity of Abp013 was tested in different concentrations $(1 \%, 5 \%, 10 \%$, and $20 \%)$ of human serum. Abp013 retained good bactericidal activity $1 \%$ serum, where Abp013 was able to achieve over 2-log CFU reduction at $25 \mu \mathrm{g} / \mathrm{mL}$ (Figure 2E). The killing efficiency was reduced when the serum concentration was raised to $5 \%$, although Abp013 still exhibited almost a 3-log CFU reduction at $100 \mu \mathrm{g} / \mathrm{mL}$. The subsequent increase in the serum concentrations to $10 \%$, greatly reduced the killing activity of Abp013 with a 1.6-log CFU reduction achieved at $400 \mu \mathrm{g} / \mathrm{mL}$ of Abp013. No significant activity was observed at $20 \%$ serum concentration.

\subsubsection{Host Lytic Spectra of Abp013}

The spectrum of bactericidal activity of Abp013 was evaluated against a panel of Gramnegative bacteria, including A. baumannii, P. aeruginosa, and K. pneumoniae at $100 \mu \mathrm{g} / \mathrm{mL}$ (Figure 3). Following an hour of incubation, Abp013 was able to eradicate and lyse all the Acinetobacter strains, including A. baumannii and A. radioresistens. Additionally, Abp013 also exhibited effective killing activity against the tested K. pneumoniae strains, achieving over 3-log CFU reductions. The same, however, was not observed in P. aeruginosa, in which negligible bactericidal activity was observed across all four tested strains. 


\subsubsection{Activity against $A$. baumannii Biofilm}

The activity of Abp013 was subsequently evaluated in A. baumannii ATCC 17961 biofilms. The biofilms were allowed to form for 3 or $24 \mathrm{~h}$ before treating with Abp013 in $20 \mathrm{mM}$ of sodium phosphate buffer, $\mathrm{pH} \mathrm{6.0,} \mathrm{for} \mathrm{another} 3 \mathrm{~h}$. The growth curve of the biofilm was recorded (Supplementary Figure S3). The initial control test involving the treatment of the $3 \mathrm{~h}$ and $24 \mathrm{~h}$ biofilm with colistin at $4 \times$ MIC was carried out to determine the level of resistance towards antibiotic treatment. The $3 \mathrm{~h}$ biofilm showed some levels of resistance towards the colistin treatment, whereas the $24 \mathrm{~h}$ biofilm was not eradicated (Supplementary Figure S4). Following Abp013 treatment, 400, 800, and $1600 \mu \mathrm{g} / \mathrm{mL}$ of Abp013 were able to reduce the $3 \mathrm{~h}$ biofilm CFU by 2.65- $\log (99.78 \%), 2.23-\log (99.42 \%)$, and 1.51-log $(96.93 \%)$, respectively, compared to the untreated control (Figure $4 \mathrm{~A})$. The activity of the lysin against the $3 \mathrm{~h} \mathrm{~A}$. baumannii biofilms were further verified using confocal microscopy and LIVE/DEAD staining, which indicated that $96.86 \%$ of the cells within the biofilm were dead (Figure 5). Figure $4 \mathrm{~B}$ shows that Abp013 is less effective in treating mature biofilms at a $24 \mathrm{~h}$ time point, but higher concentrations of the lysin $(800-1600 \mu \mathrm{g} / \mathrm{mL})$ could nevertheless reduce the $24 \mathrm{~h}$ biofilm CFU by $0.827-\log (85.13 \%)$ and $0.777-\log (83.32 \%)$. No CFU reduction was observed with $400 \mu \mathrm{g} / \mathrm{mL}$ Abp013 treatment. Planktonic cells collected from the $24 \mathrm{~h}$ timepoint were comparatively more susceptible to lysin treatment, and 400, 800 , and $1600 \mu \mathrm{g} / \mathrm{mL}$ of Abp013 resulted in a corresponding reduction in CFU by 92.41 , 93.80, and $98.27 \%$, respectively.

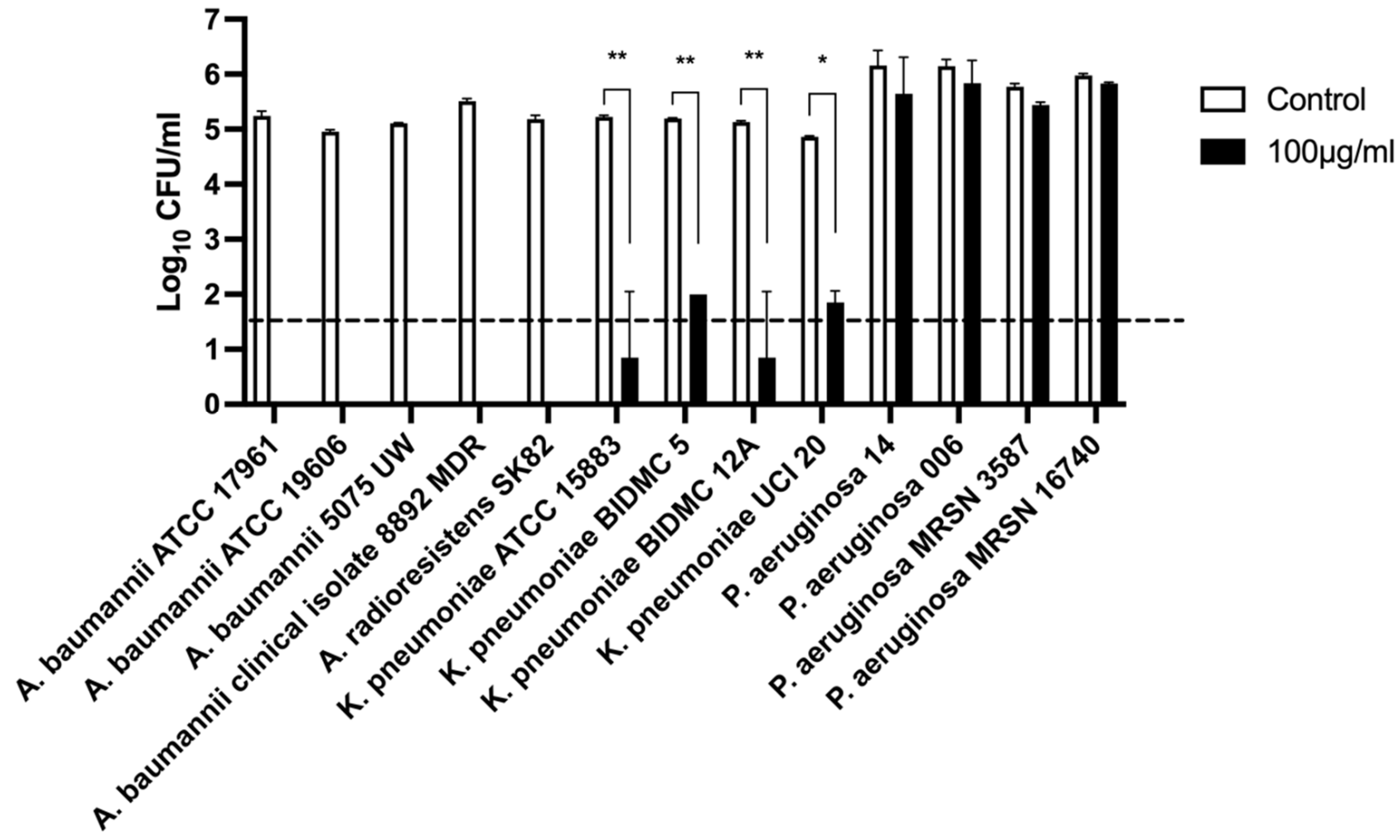

Figure 3. Lytic spectra of Abp013. A total of 4 A. baumanniii, 1 A. radioresistens, 4 P. aeruginosa, and 4 K. pneumoniae strains were incubated with $100 \mu \mathrm{g} / \mathrm{mL}$ of $\mathrm{Abp} 013$ in $20 \mathrm{mM}$ sodium phosphate buffer, $\mathrm{pH}$ 6.0, for an hour at $37^{\circ} \mathrm{C}$. The number of residual $\log 10 \mathrm{CFU} / \mathrm{mL}$ was determined through plating 10 -fold serial dilution in a bactericidal assay and compared with buffer-treated negative controls. Statistical significance was determined by a two-tailed Student's $t$-test with Welch's correction. ${ }^{*} p<0.05 ;{ }^{* *} p<0.01$. The dashed line indicates the limit of detection. The experiments were carried out in duplicates; error bars represent the standard deviation. 
A

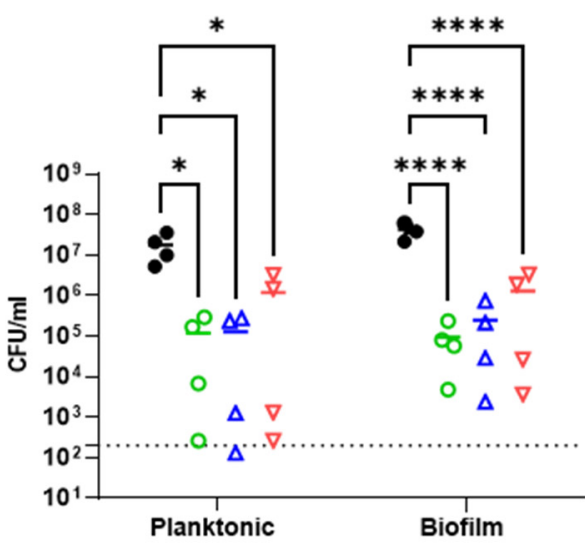

B

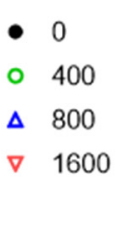

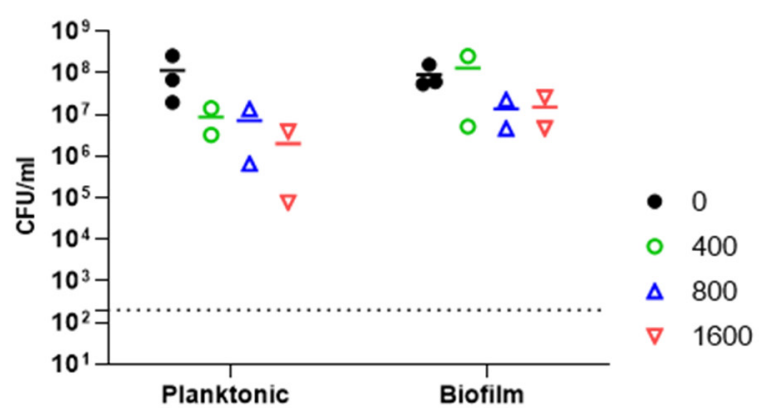

Figure 4. The effect of $3 \mathrm{~h}$ treatment of Abp013 on A. baumannii ATCC 17961 biofilm that has been pre-grown for $3 \mathrm{~h}(\mathbf{A})$ or $24 \mathrm{~h}$ (B). Both planktonic and biofilm cells were collected from the same sample well, with planktonic cells referring to the suspended cells present in the treatment buffer prior to the washing and collection of biofilm cells. Statistical significance was determined using a two-way ANOVA with multiple comparison across treatment groups. ${ }^{*} p<0.05 ;{ }^{* * *} p<0.0001$. The dashed line indicates the limit of detection. A total of 4 and 2 independent experiments were carried out for $3 \mathrm{~h}$ (A) and $24 \mathrm{~h}$ (B) biofilms, respectively, each with 2 technical replicates. Each data point represents the averaged data of an independent experiment.

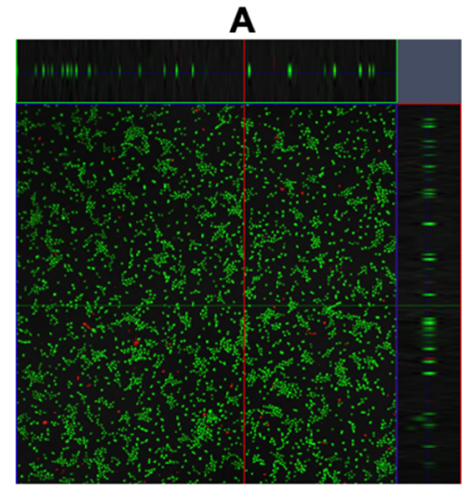

Untreated control

C

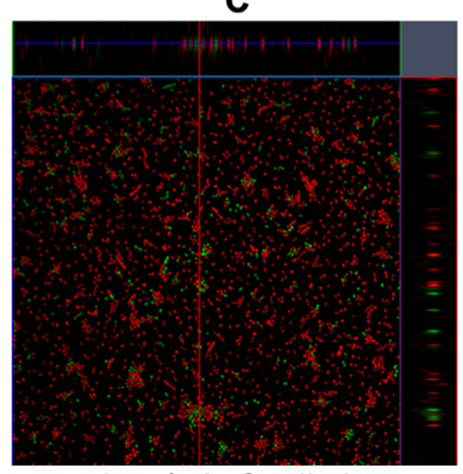

$4 \mu \mathrm{g} / \mathrm{ml}$ of colistin

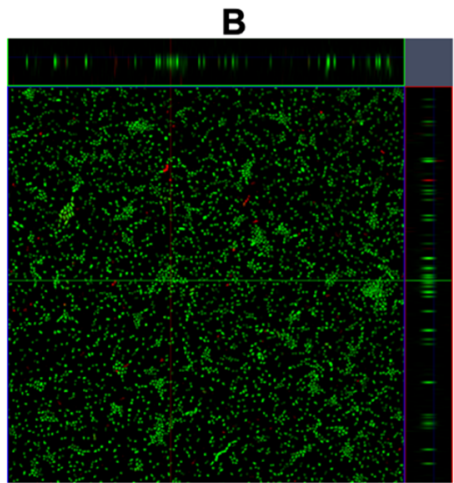

Buffer-treated control

D

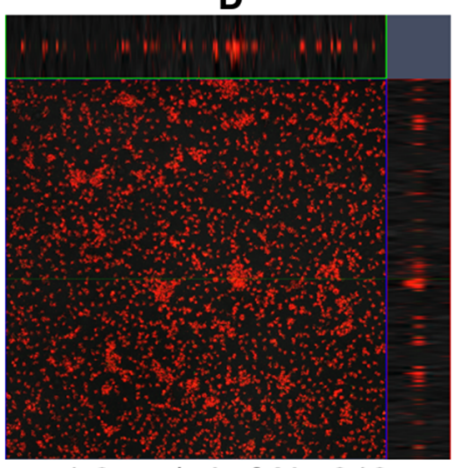

$1.6 \mathrm{mg} / \mathrm{ml}$ of $\mathrm{Abp} 013$
E

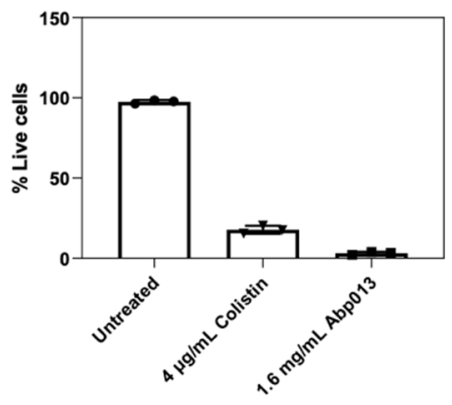

Figure 5. Representative confocal image of untreated control (A), buffer-treated control (B), $4 \mu \mathrm{g} / \mathrm{mL}$ of colistin (C), and $1.6 \mathrm{mg} / \mathrm{mL} \mathrm{Abp} 013$ (D), and the corresponding percentage of live cells (E) based on the analysis of at least 3 images for each treatment sample. 


\section{Discussion}

In this study, we identified and characterized a novel phage lysin Abp013, revealing its natural intrinsic lytic activity against $A$. baumannii and K. pneumoniae bacterial strains. Abp013 exhibits the ability to kill the bacterial cells in established biofilms, suggesting the therapeutic potential as an alternative antimicrobial agent against MDR Gram-negative pathogens in clinical settings.

Interestingly, the host range spectra of $\mathrm{Abp} 013$ revealed significant lytic activity against A. baumannii and K. pneumoniae, but not against P. aeruginosa. Other than Abp013, Ply6A3 was previously observed to be effective against many A. baumannii and K. pneumoniae strains, but found to be ineffective against $P$. aeruginosa strains [30]. The absence of the antibacterial activity of Abp013 against $P$. aeruginosa remains largely unknown. However, we ruled out the possibility that the lack of activity against $P$. aeruginosa is due to the catalytic domain of Abp013. Induced lysate clearance assay performed on autoclaved P. aeruginosa bacterial agar showed that Abp013 formed a zone of clearance, and thus Abp013 is catalytically capable of hydrolyzing the peptidoglycan of P. aeruginosa (Supplementary Figure S5). Therefore, the selective nature of Abp013 likely stems from the cationic C-terminal of Abp013. The differences in the molecular architecture and the diversity of the LPS among Gram-negative bacteria could affect the permeability of the outer membrane, thereby obstructing the entry of Abp013 [18,31]. Understanding such a mechanism requires the structural and dynamic information of the lysin-membrane interactions.

Despite being listed as part of the global priority list by the WHO, few lysins have been reported to be active against K. pneumoniae due to its thick capsular polysaccharide layer on the outer cell wall [32]. As such, it is encouraging for Abp013 to exhibit good killing activity against multiple strains of K. pneumoniae. As the C-terminal region of Abp013 consists of 9 positively charged residues, we reckon that the positively charged tail of Abp013 may have played a role in anchoring the lysin to the capsular polysaccharide produced by K. pneumoniae and the outer membrane of A. baumannii, thereby enhancing the permeability.

The $\mathrm{pH}$ characterization showed that $\mathrm{Abp013}$ is active between $\mathrm{pH}$ 6.0-9.0. Interestingly, Abp013 showed significantly lower activity at $\mathrm{pH}$ 7.0. However, we could not pinpoint a mechanism that could explain such an observation. Abp013 is positively charged at $\mathrm{pH} 7$ with an isoelectric point of 9.5, thereby ruling out the possibility of Abp013 crashing out due to a loss of charge. Similar observations were also reported by Wu et al. [30], which saw the increase in the turbidity of Ply6A3 at $\mathrm{pH} 6.5$ and 7.5, but a decrease at $\mathrm{pH} 7.0$. A dose-response assay showed that Abp013 was able to reduce the amount of bacterial cells at $50 \mu \mathrm{g} / \mathrm{mL}$, below the limit of detection of $50 \mathrm{CFU} / \mathrm{mL}$. Encouragingly, a low lysin concentration required for antibacterial activity would provide a lower production cost for future translation into commercialization [20].

Environmental factors, such as proteins and salts, can significantly influence the lytic activity of Gram-negative lysins. We showed the significant loss of lytic activity of Abp013 in $\mathrm{NaCl}$ concentrations above $100 \mathrm{mM}$, suggesting a low halotolerance. This may be attributed to the electrostatic screening that is imposed by the salt ions that are present in excess. The electrostatic screening thus potentially shields the peptidoglycan layer from Abp013, thereby weakening the electrostatic interaction needed by lysins to bind to the peptidoglycan to exert its lytic capability [33]. Furthermore, in a complex medium, such as human serum, the robust bactericidal activity of Abp013 was observed up until 5\% serum, which is better than the results from many previously reported Gram-negative lysins, such as PlyPa03 and PlyE146, with the abolishment of lytic activity observed at $1 \%$ serum $[34,35]$. As Abp013 gradually loses its antibacterial activity above $10 \%$ serum concentration, the clinical usage of Abp013 is limited to topical applications, where the direct exposure to serum components is minimal as opposed to a systemic mode of administration [35]. Despite this limitation, the bacteriolytic capacity of Abp013 in low serum conditions offers an exciting possibility of the systemic use of lysins, if the lysins can be further engineered to tolerate higher serum or salt concentrations. Gerstmans et al. [36] reported the production 
of engineered lysins that are effective in killing several A. baumannii strains in up to $90 \%$ human serum.

The common observation of the loss of lytic activity imposed by the serum could be explained by the presence of negatively charged molecules found in the serum, resulting in the conjugation and passivation of positively charged residues commonly found in the binding domain of Gram-negative lysins. The resultant neutralized domain would be unable to bind to the negatively charged peptidoglycan, causing the inherent loss of the lysins' intrinsic ability to permeabilize the outer membrane of Gram-negative bacteria.

The ability for A. baumannii to form biofilms aids in its propagation as a widespread nosocomial pathogen [37]. As it has been postulated that the biofilm eradication ability of lysins relies on the ability to kill sessile bacteria that are embedded in the biofilm matrix, the dispersing and destruction of the structural integrity of the bacterial cells could also aid in biofilm destabilization [38]. In this study, the bacteriolytic activity of Abp013 against A. baumannii biofilms showed that Abp013 exhibited the ability to gain access and lyse the bacterial cells residing in the biofilm in a dose-dependent manner. While Abp013 was effective in achieving a significant $\log \mathrm{CFU}$ reduction in the $3 \mathrm{~h}$ biofilm, its efficacy was reduced when treating mature biofilms at the $24 \mathrm{~h}$ time point, with higher concentrations needed to achieve $\sim 85 \%$ of the total CFU reduction. As the growth of biofilms are often dynamic, one determining factor in the outcome of therapeutic regimens is often the age of the biofilms [39]. Older and mature biofilms are known to be less susceptible to antimicrobial agents than younger biofilms and planktonic cells, due to a difference in their metabolic activity and stress response towards antimicrobials $[40,41]$. This was concordant with our observations that the susceptibility of the biofilm towards Abp013 decreased when the growth time increased from the 3 to $24 \mathrm{~h}$ timepoint. Studies conducted by Lood et al. [14] and Raz et al. [35] showed that stationary phase cells were generally more resistant to lysin treatment, which was evident in the significant decrease in activity of Abp013 on the stationary planktonic cells ( $24 \mathrm{~h}$ timepoint), as compared to the $3 \mathrm{~h}$ planktonic cells. Interestingly, several studies reporting Gram-negative lysins with an observed efficacy towards biofilm reduction have a different secondary structure make-up from Abp013. For instance, PlyF307 contained a single lysozyme domain and a cationic peptide located in the C-terminal [19], while Abtn-4 contained the glycoside hydrolase family 19 domain and an amphipathic helix at the C-terminal [22].

In summary, we reported Abp013, a novel phage lysin that displays host selectivity, a rare feature in Gram-negative lysins. Unraveling the mechanism behind the lack of killing against $P$. aeruginosa would require future investigations of the structure of Abp013 and its binding dynamics onto various bacterial membranes. These mechanistic understanding will guide protein engineers to design suitable variants with customized selectivity to only targeting the pathogenic bacteria. Given the modular nature of Abp013, it opens the possibility for the efficient swapping of the binding or catalytic domain with other lysins, antimicrobial components, or fusion with antimicrobial peptides, resulting in an engineered chimeric lysin that may display superior antimicrobial potency with improved activity, expanded host spectrum, and robust activity in physiological conditions [19,42].

\section{Materials and Methods}

\subsection{The Bacterial Strains and Growth Conditions}

The bacterial strains utilized in this study are listed in Table 1 . The bacterial strains were procured from the American Type Culture Collection (ATCC), Biodefense and Emerging Infections Research Resources Repository (BEI), and the Singapore General Hospital, Department of Microbiology. The bacteria were grown in either liquid broth (shaking at $200 \mathrm{rpm}$ ) or solid agar medium consisting of Luria-Bertani (LB) broth at $37^{\circ} \mathrm{C}$. The bacterial strains were suspended in LB broth containing $50 \%$ glycerol and maintained at $-80{ }^{\circ} \mathrm{C}$ for long-term storage. 
Table 1. Bacterial strains employed in this study.

\begin{tabular}{cc}
\hline Strain & Reference/Source \\
\hline A. baumannii ATCC 17961 & BEI \\
\hline A. baumannii ATCC 19606 & BEI \\
\hline A. baumannii 5075-UW & BEI \\
\hline A. baumannii clinical isolate 8879 MDR & Singapore General Hospital, Department of Microbiology \\
\hline A. radioresistens SK82 & BEI \\
\hline P. aeruginosa MRSN 16740 & BEI \\
\hline P. aeruginosa MRSN 3587 & BEI \\
\hline P. aeruginosa 006 & Singapore General Hospital, Department of Microbiology \\
\hline P. aeruginosa 14 & BEI \\
\hline K. pneumoniae ATCC 13883 & ATCC \\
\hline K. pneumoniae BIDMC 5 & BEI \\
\hline K. pneumoniae BIDMC 12A & BEI \\
\hline
\end{tabular}

\subsection{Bioinformatics Analysis}

The nucleotide sequences of Abp013 and 20 others previously reported that Gramnegative lysins were downloaded from the NCBI database and aligned using the ClustalW alignment on the MEGA11 software. These sequences were compared by the NeighborJoining method [43]. The bootstrap consensus tree inferred from 1000 replicates was used to represent the evolutionary history of the analyzed taxa [44]. The branches corresponding to the partitions reproduced in less than $50 \%$ of the bootstrap replicates were collapsed. The percentage of replicate trees in which the associated taxa clustered together in the bootstrap test were expressed next to the branches [44]. The evolutionary distances were computed based on the p-distance method [45] and expressed as the number of base differences per site. The codon positions included consist of $1 s t+2 n d+3 r d+$ noncoding, and all the ambiguous positions were removed for each sequence pair via the pairwise deletion option. There was a total of 989 positions in the final dataset. Evolutionary analyses were conducted in MEGA11 [46]. The functional domain analysis of Abp013 was carried out using the NCBI CDD [47] and SMART [48].

\subsection{Cloning, Expression, and Purification of Abp013}

The Abp013 gene was synthesized and cloned into the pNIC-CH expression vector by Bio Basic Inc. (Markham, ON, Canada). The nucleotide sequences were codon-optimized for the E. coli expression system to improve the overall efficacy of the soluble expression. The amino acid sequence for Abp013 can be found in Supplementary Table S2. The recombinant Abp013 fused to a $6 \times$ HIS tag at the C-terminal was transformed into BL21(DE3)-T1R E. coli competent cells for efficient expression. The transformed cells were incubated in $15 \mathrm{~mL}$ of LB broth at $37^{\circ} \mathrm{C}$ containing $50 \mu \mathrm{g} / \mathrm{mL}$ of kanamycin and $34 \mu \mathrm{g} / \mathrm{mL}$ of chloramphenicol, and harvested once the mid-log phase of $\mathrm{OD}_{600} 0.5-0.6$ was reached. A total of $5 \mathrm{~mL}$ of culture was added to an autoinduction media $(47.6 \mathrm{~g} / \mathrm{L}$ of Terrific Broth, $5 \mathrm{~g} / \mathrm{L}$ $\mathrm{NaCl}, 0.15 \mathrm{~g} / \mathrm{L} \mathrm{MgSO}_{4}, 3.3 \mathrm{~g} / \mathrm{L}\left(\mathrm{NH}_{4}\right)_{2} \mathrm{SO}_{4}, 0.5 \%$ glycerol, $0.05 \%$ glucose, and $0.2 \%$ lactose) containing $50 \mu \mathrm{g} / \mathrm{mL}$ of kanamycin and $34 \mu \mathrm{g} / \mathrm{mL}$ of chloramphenicol; and subsequently incubated at $25^{\circ} \mathrm{C}$ for 3 days at $220 \mathrm{rpm}$. The cells were collected by centrifugation at $4000 \times g$ for $25 \mathrm{~min}$ at $4{ }^{\circ} \mathrm{C}$, and the cell pellet was stored at $-80^{\circ} \mathrm{C}$ until purification was carried out.

The protein was purified by resuspending the cell pellet with $10 \mathrm{~mL}$ of lysis buffer (50 mM HEPES pH 7.5, $500 \mathrm{mM} \mathrm{NaCl}, 0.5 \mathrm{mM}$ dithiothreitol (DTT), 5\% glycerol) for every gram of pellet, and $\frac{1}{2}$ tablet of the Pierce ${ }^{\mathrm{TM}}$ protease inhibitor (Thermo Fisher Scientific, 
Waltham, MA, USA), before disrupting it by sonication on ice. The cell debris was removed via centrifugation at $20,000 \times g$ for an hour at $4{ }^{\circ} \mathrm{C}$ to obtain the soluble proteins. The supernatant was subsequently filtered with a $0.22 \mu \mathrm{m}$ pore size filter (Sartorius Stedim Biotech, Gottingen, Germany) and incubated with $3 \mathrm{~mL}$ of nickel-charged magnetic beads (GenScript, Piscataway, NJ, USA) for $2 \mathrm{~h}$ at $4{ }^{\circ} \mathrm{C}$ in a tube rotator. The desired proteins were then washed and eluted with lysis buffers containing $0,10,20,250$, and $500 \mathrm{mM}$ of imidazole. The purity of the collected fractions was evaluated via sodium dodecyl sulfate-polyacrylamide gel electrophoresis (SDS-PAGE) on a 12\% gel and later stained with Coomassie Brilliant Blue-R250. The purified protein fractions were concentrated using a Vivaspin 20 Centrifugal Concentrator 10,000 MWCO PES (Sartorius Stedim Biotech, Gottingen, Germany) to a concentration of $>5 \mathrm{mg} / \mathrm{mL}$ before storing in aliquots at $-80{ }^{\circ} \mathrm{C}$.

\subsection{Characterization of the Lytic Activities of Abp013}

Bactericidal assay was performed in a 96-well microtiter plate to evaluate the lytic activity of Abp013. A. baumannii ATCC 17961 was employed in this study as it is a wellcharacterized reference strain with its genome sequenced [49]. The bacterial culture was inoculated from the LB solid agar medium and grown in $10 \mathrm{~mL}$ of LB broth in $37^{\circ} \mathrm{C}$ at $200 \mathrm{rpm}$. The $\mathrm{OD}_{600}$ was measured and the bacteria were subcultured into $10 \mathrm{~mL}$ of new LB broth at $\mathrm{OD}_{600}$ 0.05. Once the early logarithmic phase $\left(\mathrm{OD}_{600} 0.3-0.4\right)$ bacteria culture was reached, it was centrifuged at $2800 \times g$ at $16^{\circ} \mathrm{C}$ for $10 \mathrm{~min}$, washed twice with $20 \mathrm{mM}$ of sodium phosphate buffer, $\mathrm{pH} 6.0$, and suspended to a final concentration of $10^{6} \mathrm{CFU} / \mathrm{mL}$. To profile the dose-response of A. baumannii to Abp013, 10 lysin concentrations ranging from $0.39 \mu \mathrm{g} / \mathrm{mL}$ to $800 \mu \mathrm{g} / \mathrm{mL}$ were diluted in the same buffer and added to the bacteria with an equal volume ratio of 1:1 in a 96-well microplate to a final volume of $100 \mu \mathrm{L}$. Upon an hour incubation at $37^{\circ} \mathrm{C}$ on an orbital shaker at $200 \mathrm{rpm}$, the Abp013-treated bacterial cells were serially diluted in 10-folds and plated on a bactericidal assay to determine the minimum inhibitory concentration (MIC). The same volume of buffer was added to the bacterial cells instead of Abp013 as part of the negative control.

To determine the optimal $\mathrm{pH}$ condition in which the maximal lytic activity of the lysin could be observed, the reference strain was treated with $100 \mu \mathrm{g} / \mathrm{mL}$ of Abp013. The pH profiling experiment was performed after the bacterial cells were washed and resuspended in $20 \mathrm{mM}$ of sodium phosphate buffer at pH 6.0 and 7.0, and $20 \mathrm{mM}$ of Tris buffer at $\mathrm{pH} 8.0$ and 9.0. Upon setting the $\mathrm{pH}$ at 6.0, the further investigation of the lytic activity under $\mathrm{NaCl}$ concentrations ranging from 0 to $500 \mathrm{mM}$ in $20 \mathrm{mM}$ of phosphate buffer, $\mathrm{pH} 6.0$, and $1 \times$ phosphate-buffered saline (PBS), pH 7.4, was carried out. The influence of the serum on the lytic activity of Abp013 was also studied under varying concentrations of human serum (Sigma Aldrich, St. Louis, MI, USA), ranging from $0 \%$ to $20 \%$ in $20 \mathrm{mM}$ of phosphate buffer, $\mathrm{pH}$ 6.0. A total of $100 \mu \mathrm{g} / \mathrm{mL}$ of $\mathrm{Abp} 013$ was chosen to determine the activity and tolerance of Abp013 towards both the salt and human serum.

The lytic activity was measured by the reduction in the $\log _{10}(\mathrm{CFU} / \mathrm{mL})$ of the viable cells enumerated after incubation with the lysin, as compared to the negative control. All the assays were performed in duplicates and the buffers were autoclaved before use. Data are expressed as the mean \pm standard deviation.

\subsection{Host Range Spectra Determination}

The spectrum of the antimicrobial activity of Abp013 $(100 \mu \mathrm{g} / \mathrm{mL})$ was evaluated against a panel of strains listed in Table 1 . All bacteria grown to the logarithmic phase were cultured, washed, and resuspended in $20 \mathrm{mM}$ of sodium phosphate, $\mathrm{pH}$ 6.0, as determined by the $\mathrm{pH}$ characterization. The experiments were carried out in duplicates and data are expressed as the mean \pm standard deviation.

\subsection{Biofilm Assay}

Biofilm assay was performed in a 24-well plate to evaluate the lytic activity of Abp013. The overnight cultures of $A$. baumannii ATCC 17961 were diluted in M9 glucose media 
(1× M9 salts, $2 \mathrm{mM} \mathrm{MgSO}_{4}, 0.1 \mathrm{mM} \mathrm{CaCl}_{2}, 0.4 \% w / v$ glucose) to a final $\mathrm{OD}_{600}$ of 0.05 . a total of $1 \mathrm{~mL}$ of the diluted culture was then added into each well of the 24-well plate and incubated at $37{ }^{\circ} \mathrm{C}$ with $100 \mathrm{rpm}$ shaking. Following 3-24 h of incubation, each well was washed once and the culture media was replaced with $1 \mathrm{~mL}$ of $20 \mathrm{mM}$ sodium phosphate, $\mathrm{pH}$ 6.0, containing $0-1600 \mu \mathrm{g} / \mathrm{mL}$ of Abp013. The treated samples were further incubated under the same conditions for $3 \mathrm{~h}$. At $t=6 \mathrm{~h}$ or $27 \mathrm{~h}$, the samples were collected. The $20 \mathrm{mM}$ of sodium phosphate ( $\mathrm{pH}$ 6.0) buffer containing suspended bacteria cells with $0-1600 \mu \mathrm{g} / \mathrm{mL}$ Abp013 treatment was collected into $1.5 \mathrm{~mL}$ Eppendorf tubes and considered to be "planktonic samples". Subsequently, each well was washed once with $1 \mathrm{~mL}$ of $20 \mathrm{mM}$ sodium phosphate, $\mathrm{pH}$ 6.0, before resuspending the biofilm cells in the same volume of fresh $20 \mathrm{mM}$ sodium phosphate, $\mathrm{pH}$ 6.0. The biofilm cells were dislodged into the buffer by means of a cell scraper and $1 \mathrm{~mL}$ of the sample was collected into the $1.5 \mathrm{~mL}$ Eppendorf tubes and labeled "biofilm samples". The samples contained in the Eppendorf tubes were sonicated in a water bath using the following settings: 5 min degas mode, $37 \mathrm{~Hz}$, $100 \%$, followed by $5 \mathrm{~min}$ pulse mode, $37 \mathrm{~Hz}, 100 \%$. Subsequently, the samples were serially diluted and used for CFU counts.

\subsection{Confocal Microscopy}

The biofilm was grown and treated, as described above, using a microscopy compatible 24-well plate ( $\mu$-plate 24-well black plate, Cat no. 82426, Ibidi). Following the treatment, each well was washed once with $20 \mathrm{mM}$ of sodium phosphate, $\mathrm{pH}$ 6.0. Each well was then stained with $200 \mu \mathrm{L}$ of LIVE/DEAD stain (L7012, Thermo Fisher, Waltham, MA, USA) that was freshly prepared according to the manufacturer's instructions. Confocal microscopy was carried out using a Carl Zeiss confocal laser scanning microscope LSM 780. Images were obtained using a LD Plan-Neofluar $40 \times / 0.6$ dry objective and analyzed using Imaris (Version 8.0.2).

\subsection{Statistical Analysis}

A two-tailed Student's $t$-test with Welch's correction was used to evaluate the statistical significance of the obtained results. A $p$-value of $<0.05$ was considered statistically significant $\left({ }^{*} p<0.05 ;{ }^{* *} p<0.01 ;{ }^{* * *} p<0.001\right)$. CFU counts in the biofilm assays were analyzed using Graphpad Prism V9.3.0 using 2-way ANOVA and a multiple comparison of column effect (concentration of Abp013) within each row (planktonic vs. biofilm samples).

Supplementary Materials: The following are available online at https:/ / www.mdpi.com/article/ 10.3390/antibiotics11020169/s1, Figure S1: sequence alignment of Abp013 with two similar lysins, Figure S2: additional pH profiling, Figure S3: biofilm growth curve of A. baumannii ATCC 17961, Figure S4: effect of colistin treatment on early and mature biofilms, Figure S5: induced lysate clearance assay of the P. aeruginosa strain PA14, Table S1: domain prediction of Abp013 using SMART analysis, Table S2: amino acid sequence of Abp013 used in this study.

Author Contributions: Conceptualization, B.C.G.; investigation, J.J.K.C., W.H.P., N.T.B.H., E.Y.H., L.C.D., A.E.S.; formal analysis, J.J.K.C., W.H.P., N.T.B.H., B.C.G.; writing-original draft preparation, J.J.K.C., W.H.P.; writing-review and editing, J.J.K.C., W.H.P., S.A.R., B.C.G.; supervision, S.A.R., B.C.G.; funding acquisition, A.E.S., S.A.R., B.C.G. All authors have read and agreed to the published version of the manuscript.

Funding: This research was funded by the Intra-CREATE Seed Collaboration Grant, ITS-006-003, and the Antimicrobial Resistance IRG of the Singapore-MIT Alliance for Research and Technology Centre, supported by the National Research Foundation, Prime Minister's Office, Singapore under its Campus for Research Excellence and Technological Enterprise (CREATE) Program.

Institutional Review Board Statement: Not applicable.

Informed Consent Statement: Not applicable.

Acknowledgments: The authors would like to acknowledge the financial support from the National Research Foundation and Ministry of Education Singapore under its Research Centre of Excellence 
Program. The authors would like to thank Andrea Kwa at the Singapore General Hospital, Dept of Microbiology for the clinical isolates. The authors would like to thank Jade Lam and Abirami R for their assistance in the lab.

Conflicts of Interest: The authors declare no conflict of interest.

\section{References}

1. Woolhouse, M.; Ward, M.; van Bunnik, B.; Farrar, J. Antimicrobial resistance in humans, livestock and the wider environment. Philos. Trans. R. Soc. Lond. B Biol. Sci. 2015, 370, 20140083. [CrossRef] [PubMed]

2. Venter, H.; Henningsen, M.L.; Begg, S.L. Antimicrobial resistance in healthcare, agriculture and the environment: The biochemistry behind the headlines. Essays Biochem. 2017, 61, 1-10. [CrossRef] [PubMed]

3. GBD 2016 Lower Respiratory Infections Collaborators. Estimates of the global, regional, and national morbidity, mortality, and aetiologies of lower respiratory infections in 195 countries, 1990-2016: A systematic analysis for the Global Burden of Disease Study 2016. Lancet Infect. Dis. 2018, 18, 1191-1210. [CrossRef]

4. Tacconelli, E.; Carrara, E.; Savoldi, A.; Harbarth, S.; Mendelson, M.; Monnet, D.L.; Pulcini, C.; Kahlmeter, G.; Kluytmans, J.; Carmeli, Y.; et al. Discovery, research, and development of new antibiotics: The WHO priority list of antibiotic-resistant bacteria and tuberculosis. Lancet Infect. Dis. 2018, 18, 318-327. [CrossRef]

5. Shrivastava, S.; Shrivastava, P.; Ramasamy, J. World health organization releases global priority list of antibiotic-resistant bacteria to guide research, discovery, and development of new antibiotics. J. Med. Soc. 2018, 32, 76-77. [CrossRef]

6. Magiorakos, A.P.; Srinivasan, A.; Carey, R.B.; Carmeli, Y.; Falagas, M.E.; Giske, C.G.; Harbarth, S.; Hindler, J.F.; Kahlmeter, G.; Olsson-Liljequist, B.; et al. Multidrug-resistant, extensively drug-resistant and pandrug-resistant bacteria: An international expert proposal for interim standard definitions for acquired resistance. Clin. Microbiol. Infect. 2012, 18, 268-281. [CrossRef]

7. Heselpoth, R.D.; Swift, S.M.; Linden, S.B.; Mitchell, M.S.; Nelson, D.C. Enzybiotics: Endolysins and Bacteriocins. In Bacteriophages: Biology, Technology, Therapy; Harper, D.R., Abedon, S.T., Burrowes, B.H., McConville, M.L., Eds.; Springer International Publishing: Cham, Switzerland, 2021; pp. 989-1030.

8. Tafoya, D.A.; Hildenbrand, Z.L.; Herrera, N.; Molugu, S.K.; Mesyanzhinov, V.V.; Miroshnikov, K.A.; Bernal, R.A. Enzymatic characterization of a lysin encoded by bacteriophage EL. Bacteriophage 2013, 3, e25449. [CrossRef]

9. Grishin, A.V.; Karyagina, A.S.; Vasina, D.V.; Vasina, I.V.; Gushchin, V.A.; Lunin, V.G. Resistance to peptidoglycan-degrading enzymes. Crit. Rev. Microbiol. 2020, 46, 703-726. [CrossRef]

10. Dams, D.; Briers, Y. Enzybiotics: Enzyme-Based Antibacterials as Therapeutics. Adv. Exp. Med. Biol. 2019, 1148, 233-253. [CrossRef]

11. Binte Muhammad Jai, H.S.; Dam, L.C.; Tay, L.S.; Koh, J.J.W.; Loo, H.L.; Kline, K.A.; Goh, B.C. Engineered Lysins With Customized Lytic Activities against Enterococci and Staphylococci. Front. Microbiol. 2020, 11, 574739. [CrossRef]

12. Yang, D.; Chen, Y.; Sun, E.; Hua, L.; Peng, Z.; Wu, B. Characterization of a Lytic Bacteriophage vB_EfaS_PHB08 Harboring Endolysin Lys08 against Enterococcus faecalis Biofilms. Microorganisms 2020, 8, 1332. [CrossRef] [PubMed]

13. Oechslin, F.; Daraspe, J.; Giddey, M.; Moreillon, P.; Resch, G. In vitro characterization of PlySK1249, a novel phage lysin, and assessment of its antibacterial activity in a mouse model of Streptococcus agalactiae bacteremia. Antimicrob. Agents Chemother. 2013, 57, 6276-6283. [CrossRef] [PubMed]

14. Lood, R.; Raz, A.; Molina, H.; Euler, C.W.; Fischetti, V.A. A highly active and negatively charged Streptococcus pyogenes lysin with a rare D-alanyl-L-alanine endopeptidase activity protects mice against streptococcal bacteremia. Antimicrob. Agents Chemother. 2014, 58, 3073-3084. [CrossRef] [PubMed]

15. Lai, M.J.; Lin, N.T.; Hu, A.; Soo, P.C.; Chen, L.K.; Chen, L.H.; Chang, K.C. Antibacterial activity of Acinetobacter baumannii phage фAB2 endolysin (LysAB2) against both gram-positive and gram-negative bacteria. Appl. Microbiol. Biotechnol. 2011, 90, 529-539. [CrossRef] [PubMed]

16. Briers, Y.; Walmagh, M.; Van Puyenbroeck, V.; Cornelissen, A.; Cenens, W.; Aertsen, A.; Oliveira, H.; Azeredo, J.; Verween, G.; Pirnay, J.P.; et al. Engineered endolysin-based “Artilysins" to combat multidrug-resistant gram-negative pathogens. $m B i o$ 2014, 5, e01379-14. [CrossRef] [PubMed]

17. Lai, W.C.B.; Chen, X.; Ho, M.K.Y.; Xia, J.; Leung, S.S.Y. Bacteriophage-derived endolysins to target gram-negative bacteria. Int. J. Pharm. 2020, 589, 119833. [CrossRef]

18. Huang, G.; Shen, X.; Gong, Y.; Dong, Z.; Zhao, X.; Shen, W.; Wang, J.; Hu, F.; Peng, Y. Antibacterial properties of Acinetobacter baumannii phage Abp1 endolysin (PlyAB1). BMC Infect. Dis. 2014, 14, 681. [CrossRef]

19. Lood, R.; Winer, B.Y.; Pelzek, A.J.; Diez-Martinez, R.; Thandar, M.; Euler, C.W.; Schuch, R.; Fischetti, V.A. Novel phage lysin capable of killing the multidrug-resistant gram-negative bacterium Acinetobacter baumannii in a mouse bacteremia model. Antimicrob. Agents Chemother. 2015, 59, 1983-1991. [CrossRef]

20. Ghose, C.; Euler, C.W. Gram-Negative Bacterial Lysins. Antibiotics 2020, 9, 74. [CrossRef]

21. Kim, S.; Jin, J.S.; Choi, Y.J.; Kim, J. LysSAP26, a New Recombinant Phage Endolysin with a Broad Spectrum Antibacterial Activity. Viruses 2020, 12, 1340. [CrossRef]

22. Yuan, Y.; Li, X.; Wang, L.; Li, G.; Cong, C.; Li, R.; Cui, H.; Murtaza, B.; Xu, Y. The endolysin of the Acinetobacter baumannii phage vB_AbaP_D2 shows broad antibacterial activity. Microb. Biotechnol. 2021, 14, 403-418. [CrossRef] [PubMed] 
23. Rotem, S.; Radzishevsky, I.; Inouye, R.T.; Samore, M.; Mor, A. Identification of antimicrobial peptide regions derived from genomic sequences of phage lysins. Peptides 2006, 27, 18-26. [CrossRef] [PubMed]

24. During, K.; Porsch, P.; Mahn, A.; Brinkmann, O.; Gieffers, W. The non-enzymatic microbicidal activity of lysozymes. FEBS Lett. 1999, 449, 93-100. [CrossRef]

25. Yang, Z.; Liu, X.; Shi, Y.; Yin, S.; Shen, W.; Chen, J.; Chen, Y.; Chen, Y.; You, B.; Gong, Y.; et al. Characterization and genome annotation of a newly detected bacteriophage infecting multidrug-resistant Acinetobacter baumannii. Arch. Virol. 2019, 164, 1527-1533. [CrossRef] [PubMed]

26. Letunic, I.; Khedkar, S.; Bork, P. SMART: Recent updates, new developments and status in 2020. Nucleic Acids Res. 2021, 49, D458-D460. [CrossRef] [PubMed]

27. Edgar, R.C. MUSCLE: Multiple sequence alignment with high accuracy and high throughput. Nucleic Acids Res. 2004, 32, 1792-1797. [CrossRef] [PubMed]

28. Obeidat, N.; Jawdat, F.; Al-Bakri, A.G.; Shehabi, A.A. Major biologic characteristics of Acinetobacter baumannii isolates from hospital environmental and patients' respiratory tract sources. Am. J. Infect. Control. 2014, 42, 401-404. [CrossRef]

29. Dekic, S.; Hrenovic, J.; Ivankovic, T.; van Wilpe, E. Survival of ESKAPE pathogen Acinetobacter baumannii in water of different temperatures and pH. Water Sci. Technol. 2018, 78, 1370-1376. [CrossRef]

30. Wu, M.; Hu, K.; Xie, Y.; Liu, Y.; Mu, D.; Guo, H.; Zhang, Z.; Zhang, Y.; Chang, D.; Shi, Y. A Novel Phage PD-6A3, and Its Endolysin Ply6A3, With Extended Lytic Activity against Acinetobacter baumannii. Front. Microbiol. 2018, 9, 3302. [CrossRef]

31. Lopez, C.A.; Zgurskaya, H.; Gnanakaran, S. Molecular characterization of the outer membrane of Pseudomonas aeruginosa. Biochim. Biophys. Acta Biomembr. 2020, 1862, 183151. [CrossRef]

32. Zhen, X.; Lundborg, C.S.; Sun, X.; Hu, X.; Dong, H. Economic burden of antibiotic resistance in ESKAPE organisms: A systematic review. Antimicrob. Resist. Infect. Control 2019, 8, 137. [CrossRef] [PubMed]

33. Shen, Y.; Barros, M.; Vennemann, T.; Gallagher, D.T.; Yin, Y.; Linden, S.B.; Heselpoth, R.D.; Spencer, D.J.; Donovan, D.M.; Moult, J.; et al. A bacteriophage endolysin that eliminates intracellular streptococci. eLife 2016, 5, e13152. [CrossRef] [PubMed]

34. Larpin, Y.; Oechslin, F.; Moreillon, P.; Resch, G.; Entenza, J.M.; Mancini, S. In vitro characterization of PlyE146, a novel phage lysin that targets Gram-negative bacteria. PLOS ONE 2018, 13, e0192507. [CrossRef]

35. Raz, A.; Serrano, A.; Hernandez, A.; Euler, C.W.; Fischetti, V.A. Isolation of Phage Lysins That Effectively Kill Pseudomonas aeruginosa in Mouse Models of Lung and Skin Infection. Antimicrob. Agents Chemother. 2019, 63, e00024-19. [CrossRef]

36. Gerstmans, H.; Grimon, D.; Gutierrez, D.; Lood, C.; Rodriguez, A.; van Noort, V.; Lammertyn, J.; Lavigne, R.; Briers, Y. A VersaTile-driven platform for rapid hit-to-lead development of engineered lysins. Sci. Adv. 2020, 6, eaaz1136. [CrossRef] [PubMed]

37. Longo, F.; Vuotto, C.; Donelli, G. Biofilm formation in Acinetobacter baumannii. New Microbiol. 2014, 37, 119-127. [PubMed]

38. Sharma, U.; Vipra, A.; Channabasappa, S. Phage-derived lysins as potential agents for eradicating biofilms and persisters. Drug Discov. Today 2018, 23, 848-856. [CrossRef]

39. Sedlacek, M.J.; Walker, C. Antibiotic resistance in an in vitro subgingival biofilm model. Oral Microbiol. Immunol. 2007, 22, 333-339. [CrossRef]

40. Ito, A.; Taniuchi, A.; May, T.; Kawata, K.; Okabe, S. Increased antibiotic resistance of Escherichia coli in mature biofilms. Appl. Environ. Microbiol. 2009, 75, 4093-4100. [CrossRef]

41. Borriello, G.; Richards, L.; Ehrlich, G.D.; Stewart, P.S. Arginine or nitrate enhances antibiotic susceptibility of Pseudomonas aeruginosa in biofilms. Antimicrob. Agents Chemother. 2006, 50, 382-384. [CrossRef]

42. Maciejewska, B.; Źrubek, K.; Espaillat, A.; Wiśniewska, M.; Rembacz, K.P.; Cava, F.; Dubin, G.; Drulis-Kawa, Z. Modular endolysin of Burkholderia AP3 phage has the largest lysozyme-like catalytic subunit discovered to date and no catalytic aspartate residue. Sci. Rep. 2017, 7, 14501. [CrossRef] [PubMed]

43. Saitou, N.; Nei, M. The neighbor-joining method: A new method for reconstructing phylogenetic trees. Mol. Biol. Evol. 1987, 4, 406-425. [CrossRef] [PubMed]

44. Felsenstein, J. Confidence Limits on Phylogenies: An Approach Using the Bootstrap. Evolution 1985, 39, 783-791. [CrossRef] [PubMed]

45. Nei, M.; Kumar, S. Molecular Phylogenetics and Evolution; Oxford University Press: New York, NY, USA, 2000.

46. Tamura, K.; Stecher, G.; Kumar, S. MEGA11: Molecular Evolutionary Genetics Analysis Version 11. Mol. Biol. Evol. 2021, 38, 3022-3027. [CrossRef] [PubMed]

47. Lu, S.; Wang, J.; Chitsaz, F.; Derbyshire, M.K.; Geer, R.C.; Gonzales, N.R.; Gwadz, M.; Hurwitz, D.I.; Marchler, G.H.; Song, J.S.; et al. CDD/SPARCLE: The conserved domain database in 2020. Nucleic Acids Res. 2020, 48, D265-D268. [CrossRef]

48. Zdobnov, E.M.; Apweiler, R. InterProScan-An integration platform for the signature-recognition methods in InterPro. Bioinformatics 2001, 17, 847-848. [CrossRef]

49. Farrow, J.M.; Pesci, E.C.; Slade, D.J. Genome Sequences for Two Acinetobacter baumannii Strains Obtained Using the Unicycler Hybrid Assembly Pipeline. Microbiol. Resour. Announc. 2021, 10, e00017-21. [CrossRef] 